\title{
Establishment and Characterization of a Continuous Human Chondrosarcoma Cell Line, ch-2879: Comparative Histologic and Genetic Studies with Its Tumor of Origin
}

\author{
Rosario Gil-Benso, Concha Lopez-Gines, José Antonio López-Guerrero, \\ Carmen Carda, Robert C. Callaghan, Samuel Navarro, Jaime Ferrer, Antonio Pellín, \\ and Antonio Llombart-Bosch
}

Department of Pathology, Medical School, University of Valencia, Valencia, Spain

\begin{abstract}
SUMMARY: Chondrosarcomas are malignant cartilage-forming tumors that represent the second most common malignant solid tumor of bone. These biologically poorly understood neoplasms vary considerably in clinical presentation and biologic behavior. Chemotherapy and radiation therapy are generally ineffective. Here we describe the establishment and characterization of a new human chondrosarcoma cell line named ch-2879, and we compare the cell line with its tumor of origin. The cell line was established from a recurrent grade 3 chondrosarcoma of the chest wall and characterized by growth kinetics and morphologic studies. Immunocytochemistry and RT-PCR were performed to examine the expression of cartilage-specific phenotypes. Genetic characterization was performed using cytogenetics, fluorescence in situ hybridization, flow cytometry, and molecular techniques for analysis of the genes implicated in cell cycle control, amplification of MDM2, CDK4, and Cyclin D1, and mutations in the p53 gene. ch-2879 cells were subcultured for more than 80 passages. They expressed vimentin, HNK-1, HBA-71, Ki-67, cyclin D1, Fli-1, S-100, p21, p27, and p53 and were negative for cytokeratin, EMA, p14, p16, MDM2, Rb, and c-erb-b2 antigens. Cytogenetically the recurrent tumor showed a hyperhaploid karyotype with clonal numerical and structural abnormalities. The sole structural abnormality was a chromosome derivative of a $t(1 ; 21)$ translocation. The cell line at passage 3 showed two populations: the hyperhaploid and an exactly duplicated, hypotriploid population. After the 18th passage, only the hypotriploid population was present. The cells expressed collagen 2. Molecular comparison of the primary and recurrent tumor evidenced an in vivo molecular change consisting of a deletion of 9 p21 genes in the recurrence, probably caused by a selection process. Because of its gene expression profile, including expression of genes implicated in chondrogenesis in uncoated plastic dishes, this cell line may prove useful for cellular and molecular studies as well as studies of chondrosarcoma characterization and treatment. (Lab Invest 2003, 83:877-887).
\end{abstract}

$C$ hondrosarcomas (CS) are relatively rare, malignant cartilage-forming tumors, generally presenting between 35 and 60 years of age (Dorfman and Czerniak, 1995). CS is the second most frequent primary malignant bone tumor after osteosarcoma and represents approximately $11 \%$ of all of these tumors (Aigner, 2002; Aigner et al, 2002). Histologically they are classified into three grades that correlate with prognosis (Evans et al, 1977). In patients with grades 2 and 3 tumors, local recurrence, increasing tumor size, DNA ploidy abnormality, and dedifferentiation have been associated with lower survival rates (Lee et al, 1999). In addition to cytomorphologic criteria, expression pattern analysis of matrix genes, in

DOI: 10.1097/01.LAB.0000073131.34648.EA

Received March 21, 2003.

This work was supported by a grant from the Fondo de Investigación Sanitaria FIS 01/0673, Madrid, Spain.

Address reprint requests to: Dr. Antonio Llombart-Bosch, Departamento de Patologia, Facultad de Medicina y Odontología, Avenida. Blasco Ibañez 17, Valencia 46010,Spain.E-mail:antonio.llombart@uv.es particular of the collagen types, plays a leading role in the classification and diagnosis of CS (Aigner, 2002). These biologically poorly understood malignant neoplasms vary considerably in clinical presentation and biologic behavior (Johnson et al, 1986; Martin et al, 2002). Conventional treatments for malignancy, such as current chemotherapy drugs and radiation therapy, are generally ineffective in the treatment of CS (Johnson et al, 1986; Lee et al, 1999).

The cytogenetic data on CS are heterogeneous, with chromosome numbers ranging from hyperhaploidy to near pentaploidy (Bridge et al, 1993; Johnson et al, 1986; Mandahl et al, 2002; Mitelman et al, 2002). The karyotypic complexity also varies widely, with some tumors showing a single numerical or structural chromosome aberration and others with grossly rearranged karyotypes. Gains and losses of chromosomes or segments of chromosomes are the most frequent anomalies. Specific chromosomal rearrangements have been identified only in extraskeletal myxoid CS that are characterized by $\mathrm{t}(9 ; 22)(\mathrm{q} 22 ; \mathrm{q} 12)$ (Hirabayashi et al, 1995; Turc-Carel et al, 1988) or more rarely $\mathrm{t}(9 ; 17)(\mathrm{q} 22 ; \mathrm{q} 11)$ and $\mathrm{t}(9 ; 15)(\mathrm{q} 22 ; \mathrm{q} 21)$, resulting in the 
formation of the fusion genes EWS/CHN, RBP56/ CHN, and TCF/CHN, respectively (Labelle et al, 1995; Stenman et al, 1995). DNA flow cytometry has demonstrated a wide variation in the ploidy status in CS, with a relatively frequent presentation of near haploidy (Bovee et al, 1999, 2000; Mandahl et al, 2002).

Molecular alterations of the regulatory genes implicated in cell cycle control play an important role in human tumorigenesis. Mutations of the p53 tumor suppressor gene are the most common genetic alteration in human tumors, followed by the genetic alterations of the 9p21 locus that have been demonstrated in a wide variety of neoplasms (López-Guerrero et al, 2001). p14 ${ }^{\mathrm{ARF}}$ protein is a potent regulator of the cell cycle, acting upstream in the p53 pathway by binding to MDM2 and preventing p53 degradation, thus permitting p53-induced apoptosis or growth arrest (Lundberg and Weinberg, 1999; Sharpless and DePinho, 1999). $\mathrm{p} 16^{\mathrm{INK} 4 \mathrm{~A}}$ and $\mathrm{p} 15^{\mathrm{INK} 4 \mathrm{~B}}$ are important regulators that inhibit the action of the cyclin-dependent kinases (CDK) 4 and 6 in the G1 phase of the cell cycle. CDK4 and CDK6, in turn, bind to D-type cyclins forming active complexes that phosphorylate pRb (Sharpless and DePinho, 1999). Numerous investigations have shown alterations of the p53 gene in CS, although no clinical relevance was observed (Aigner, 2002). On the contrary, only a few reports have analyzed alterations in the 9p21 locus genes. These studies showed that hypermethylation of the $\mathrm{p} 16^{\mathrm{INK} 4 \mathrm{~A}}$ gene is found predominantly in high-grade CS (Asp et al, 2000, 2001b).

Establishment of a cell line from CS is unusual. Few permanent cell lines of human CS carrying cartilage phenotypes have been reported (Chano et al, 1998; Chansky et al, 1998; Kunisada et al, 1998; Takigawa et al, 1989, 1991). We report the establishment of a new human cell line, named ch-2879, from a CS of the chest wall and its characterization by cytogenetic and molecular studies, flow cytometry, immunocytochemistry, and light and electron microscopy.

\section{Results}

\section{Morphologic Studies}

Grossly, the primary tumor showed marked destruction of the affected rib, breaking through the cortex and forming a soft tissue mass in the chest wall, measuring $8.5 \mathrm{~cm}$ at its largest dimension. The neoplasm disclosed a polylobulated appearance, with wide areas of necrosis and cystic change, filled with a mucoid material. Microscopically, the neoplasm showed a great number of small, polygonal cells, interspersed in a myxoid matrix (Fig. 1A). The cells were vaguely arranged in chords and nests, with a pale eosinophilic cytoplasm and a round, hyperchromatic nucleus. Focally, especially in the areas permeating the trabeculae of the bone, the tumor disclosed a chondroid appearance with a dense, eosinophilic matrix and large atypical chondrocytes. The tumor was diagnosed as conventional CS grade 3 . The recurrent tumor was composed of a more dense population of small cells, arranged in chords and sheets separated by a myxoid material (Fig. 1B). The mitotic activity was increased (26 mitoses/10 highpower field).

\section{Electron Microscopy}

Ultrastructurally, the tumor showed an abundant intercellular matrix. The cells were isolated or arranged in small groups (Fig. 2, A and B). A pseudobasal lamina was found focally, partially surrounding some cells. The tumoral cells had round or slightly irregular nuclei with peripheral dense chromatin and small nucleoli. The cytoplasm contained abundant rough endoplasmic reticulum, arrays of parallel microtubules, and occasionally bundles of filaments.

The ch-2879 cells showed a smooth surface and polygonal or spindle contour. They appeared closely packed to one another, forming clusters without specific cell-to-cell attachments or rudimentary tight junctions. The cells had round or oval nuclei with fine, dispersed chromatin and one or two prominent nucleoli and a scarce cytoplasm poor in organelles (Fig. 2C). Glycogen and intermediate filaments were seen, as well as numerous small lipid droplets.

\section{Establishment of Cell Line and Phase-Contrast Morphology}

The first passage of the cell line took 19 days. The cells were passaged routinely in vitro for more than 80 generations. The cells had a slightly elongated polygonal shape and grew in monolayer-forming clusters (Fig. 3, A and B). The cells showed a saturation density of $34.1 \times 10^{4}$ and a plating efficiency of $85 \%$. The mitotic index was 5.3\%. Finally, after single-cell cloning, three cell lines showing similar phenotypes were analyzed: ch-2879-A8, ch-2879-B7, and ch-2879-C1 (Fig. 3C).

\section{Immunohistochemical Characterization}

Results of the immunohistochemical studies on the primary tumor, the recurrence, the cell line, and the ch-2879-A8 cloned cells are shown in Table 1 and Figure 1. ch-2879 cells were also positive for cyclin D1 and Fli-1 and focally for p21 and p27. The cells were negative for p14, p16, MDM2, Rb, and c-erb-b2.

\section{Cytogenetic Studies}

Primary Tumor. Twenty metaphases were counted. The mode was in the hyperhaploid range, with 32 chromosomes. The karyotype was $32, \mathrm{X},+2,+5,+7,+15$, $+16,+19,+20, \operatorname{der}(21)(: 1 \mathrm{q} 12 \rightarrow 1 \mathrm{q} 44:: 21 \mathrm{p} 13 \rightarrow 21 \mathrm{qter})$, +22 .

Recurrence. Fifty metaphases were counted, having a range of between 30 and 64 chromosomes. Two populations were found, one in the hyperhaploid range with a modal number of 32 (47 cells) and another in the hypotriploid range with a mode of 64 (3 cells). The karyotypes were as follows: main population: $32, \mathrm{X},+2,+5,+7,+15,+16,+19,+20, \operatorname{der}(21)(: 1 \mathrm{q} 12 \rightarrow$ 1q44::21p13 $\rightarrow$ 21qter), +22 (Fig. 4A); hypotriploid 

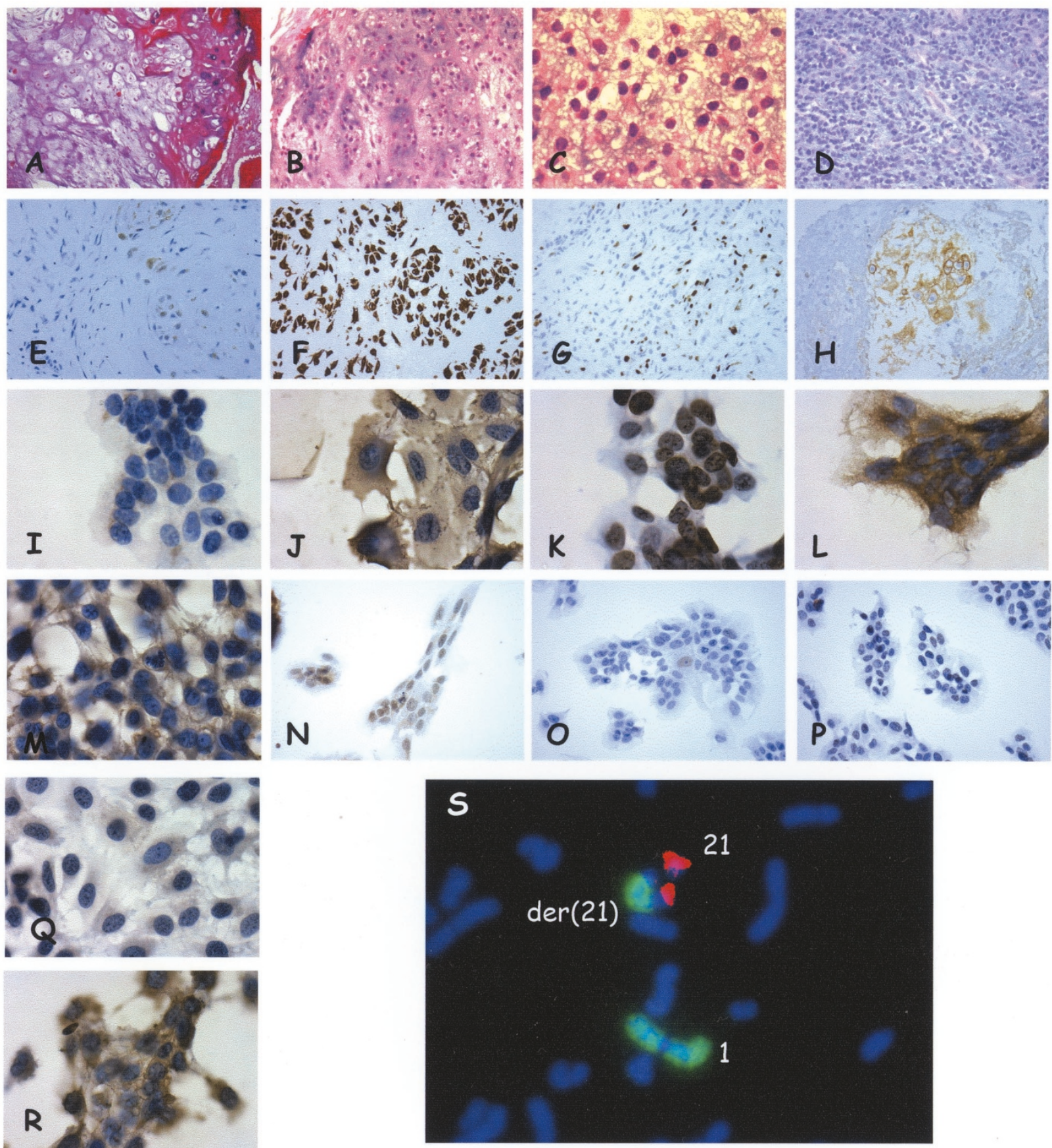

\section{Figure 1}

A, Histologic examination of the primary chondrosarcoma showing extracellular matrix-rich chondroid cells disposed in isolation or forming files or nests. HE staining original magnification $\times 20$. B, Histologic examination of local recurrence; HE $\times 20$. C, Xenotransplant from primary tumor at passage 1 ; HE $\times 40$. D, Histologic examination of tumor developed in nude mice after inoculation of ch-2879 cells, showing less differentiated cells and intratumoral blood vessels; HE $\times 20$. Immunostaining of sections of primary tumor showing S-100 (E), vimentin (F), Ki-67 (G), and HNK-1 (H). Immunostained ch-2879 cells for the following antigens: S-100 (I), vimentin (J), Ki-67 (K), HNK-1 (L), HBA-71 (M), Fli-1 (N), p21 (0), and p27 (P). Q and R, Immunostaining of cloned cells ch-2879-A8, S-100, and HNK-1, respectively. S, Fluorescence in situ hybridization using whole painting probes wcp1 SpectrumGreen and wcp21 Spectrum0range.

population: $\quad 64, \mathrm{XX},-1,+2,-3,-4,+5,-6,+7,-8,-9,-10$, $-11,-12,-13,-14,+15,+16,-17,-18, \operatorname{der}(21)(: 1 q 12 \rightarrow$ $1 \mathrm{q} 44:: 21 \mathrm{p} 13 \rightarrow 21 \mathrm{qter}),+\operatorname{der}(21)(: 1 \mathrm{q} 12 \rightarrow 1 \mathrm{q} 44:: 21 \mathrm{p} 13 \rightarrow$ 21qter), +22 . C-banding showed a positively stained region in chromosome 1q translocated with chromosome 21 (Fig. 4B).

ch-2879 Cell Line at Passage 3. Twenty-five metaphases was counted. The two populations seen in the recurrence were present: one hyperhaploid $(80 \%$ of the cells) and other hypotriploid (20\%). The karyotypes were the same as that of the recurrence.

ch-2879 at Passages 18 and 25. Twenty-five metaphases were counted in each passage; only the hypotriploid karyotype was present. The karyotype of the each clone-ch-2879-A8, ch-2879-B7, and ch-2879C1-was the same as that in the parental cell line. 


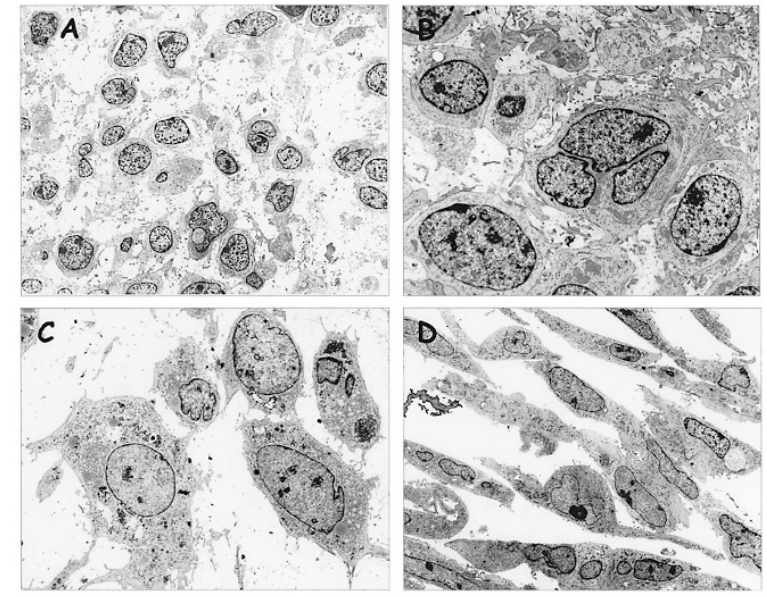

Figure 2.

$A$ and $B$, Electron micrographs of primary tumor showing abundant extracellular matrix and cells with scarce cytoplasm and large nuclei. Original magnification, $\times 1200$ and $\times 2500$, respectively. C, Xenografted tumor showing abundant extracellular matrix, $\times 2500$. D, Ultrastructural features of ch-2879 cells at passage 18 . The cells had cytoplasms with scarce organelles and nuclei with fine disperse chromatin, $\times 1200$.

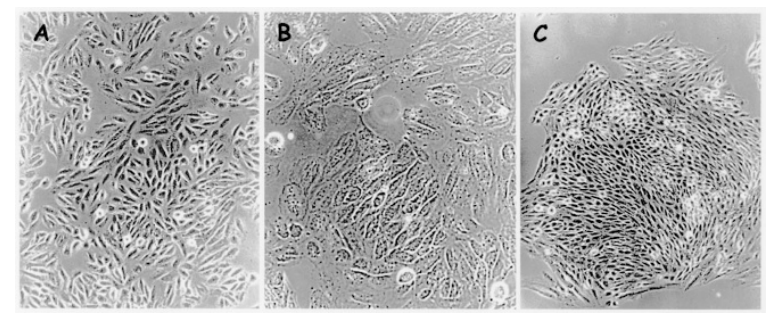

Figure 3.

Morphologic examination of ch-2879 cells at passage 14 showing a paving stone arrangement. The cells grew forming nests of small polygonal cells. Phase contrast micrographs: A, $\times 10 ; B, \times 20$. C, ch-2879-C1 cloned cells, $\times 10$.

Xenografted Primary Tumor at Passage 1. The 25 cells counted were in the hypotriploid range. The mode was 64 . The karyotype was $64, \mathrm{XX},-1,+2$, $-3,-4,+5,-6,+7,-8,-9,-10,-11,-12,-13,-14,+15$, $+16,-17,-18, \operatorname{der}(21)(: 1 \mathrm{q} 12 \rightarrow 1 \mathrm{q} 44:: 21 \mathrm{p} 11 \rightarrow 21 \mathrm{qter})$, $+\operatorname{der}(21)(: 1 q 12 \rightarrow 1 q 44:: 21 p 11 \rightarrow 21 q$ ter $),+22$. Some cells showed nonclonal abnormalities. Acentric fragments and breaks were seen.
Xenografted Tumor from Inoculated ch-2879 Cells. Twenty-five metaphases were counted. The mode was 64 . The karyotype was the same as that of the cell line.

\section{Fluorescence In Situ Hybridization}

The whole paint probes of chromosomes 1 and 21 confirmed the $\operatorname{der}(21) \mathrm{t}(1 ; 21)$ : ish $\operatorname{der}(21) \mathrm{t}(1 ; 21)$ $($ wcp $1+; w c p 21+)$ seen in the cytogenetic study (Fig. 1S).

\section{Flow Cytometry}

A DNA index of 0.64 corresponding to a hypodiploid population was obtained from the primary and recurrent tumor using human lymphocytes as ploidy control. The xenografted tumors obtained from the primary tumor showed two populations with different DNA indexes of 1.52 and 1.66. ch-2879 cells at passage 18 had a DNA index of 1.38. The ch-2879-A8 cells showed a DNA index of 1.39. The tumor obtained from nude mice by inoculation of ch-2879 cells showed a peak corresponding to a 1.29 DNA index. (Fig. 5).

\section{Molecular Biology Studies}

Analysis of RNA by RT-PCR did not reveal an EWS$\mathrm{CHN}$ or TAF2-CHN product in any of the samples analyzed. Expression of the COL2A gene was detected in the primary and recurrent tumors, the ch2879 cell line, and the xenografted tumors derived from the primary tumor (Fig. 6A). The analysis of the G1/S checkpoint elements revealed a homozygous deletion of the 9p21 locus genes (Fig. 6B), with the corresponding loss of $\mathrm{p} 16^{\mathrm{INK} 4 \mathrm{~A}}, \mathrm{p} 14^{\mathrm{ARF}}$, and $\mathrm{p} 15^{\mathrm{INK} 4 \mathrm{~B}}$ transcripts in the recurrence, and the ch-2879 cells and clones derived from it. The rest of the samples (primary tumor and xenografted tumors) were analyzed for methylation status of the $5^{\prime} \mathrm{CpG}$ island of the $\mathrm{p} 15^{\mathrm{INK} 4 \mathrm{~B}}$ and $\mathrm{p} 16^{\mathrm{INK} 4 \mathrm{~A}}$ genes, but no hypermethylation of these genes was detected. No genetic amplifications of MYCN, MDM2, Cyclin D1, or CDK4 were observed in any of the analyzed samples. None of the samples analyzed showed mutations at exons 5 to 8 of the p53 gene.

Table 1. Immunocytochemical Characterization

\begin{tabular}{llllllc}
\hline \multicolumn{1}{c}{ Antibody } & Source & \multicolumn{1}{c}{ Dilution } & P.T. & Recurrence & ch-2879 & ch-2879-A8 \\
\hline S-100 & Dako & $1: 200 / 1: 1000^{a}$ & $+(\mathrm{f})$ & $+(50 \%)$ & $+(50 \%)$ & $+(50 \%)$ \\
Ki-67 & Dako & $1: 50$ & + & + & + & + \\
HBA-71 & Signet & $1: 50$ & + & + & + & + \\
HNK-1 & ATCC & $10 \mu \mathrm{g} / \mathrm{ml}$ & + & + & + & + \\
Vimentin & Novocastra & $1: 200$ & + & + & + & + \\
EMA & Dako & $1: 50 / 1: 100^{a}$ & - & - & - & - \\
CK AE1-AE3 & Dako & $1: 200$ & - & - & - & - \\
p53 & Dako & $1: 50$ & $+(\mathrm{f})$ & $+(\mathrm{f})$ & - & - \\
\hline
\end{tabular}

P.T., primary tumor; (f), focal positivity.

a Dilution used in the study of the cultured cells. 


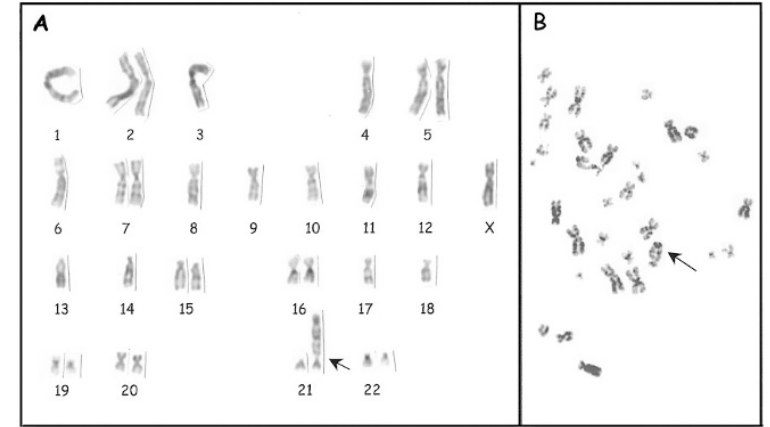

Figure 4.

A, Hyperhaploid karyotype of recurrence: $32, X,+2,+5,+7,+15,+16,+19$, $+20, \operatorname{der}(21)(: 1 q 12 \rightarrow 1 q 44:: 21 p 13 \rightarrow 21 q$ ter $),+22$. Arrow points to the only structural anomaly. B, C-banded metaphase. Arrow points to der(21) showing heterochromatin of chromosome 1q strongly stained.

\section{Heterologous Transplantation to Nude Mice}

In nude mice inoculated with fragments of primary tumor, solid tumor masses were observed at 30 days. During 36 months, nine passages were made. Morphologically, the tumors showed a more chondroid differentiation (Fig. 1C). Ultrastructurally, immature mesenchymal-chondroid cells were seen vaguely packed in a stroma with flocculent material. The cells had cytoplasm with isolated vacuoles, lipid droplets, glycogen, and intermediate filaments. The nucleus was large, with a round or invaginated contour and fine chromatin (Fig. 2D). Occasionally there were membrane attachments with poorly differentiated desmosomes and deposits of amorphous dense material associated with collagen bands.

The injection of ch-2879 cells into congenitally athymic mice induced a visible solid tumor at the site of inoculation after 12 days, which gradually enlarged. The tumor presented microscopically and ultrastruc-
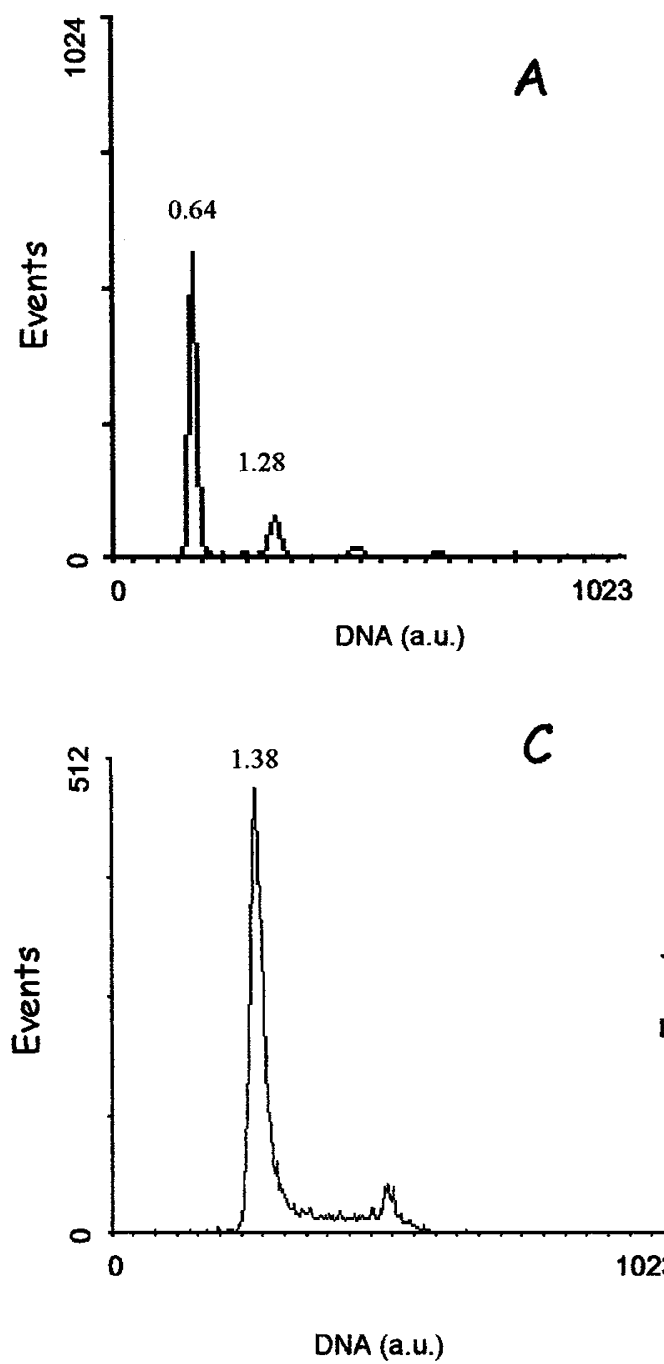

B 1.52

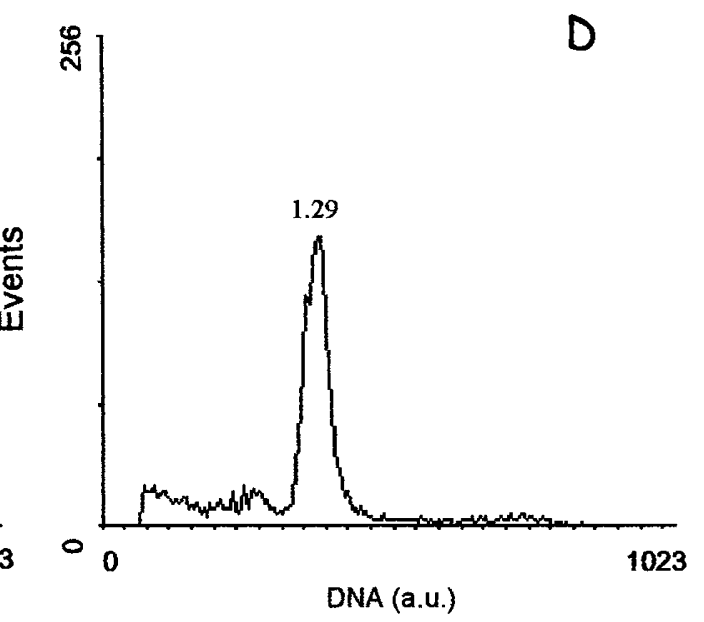

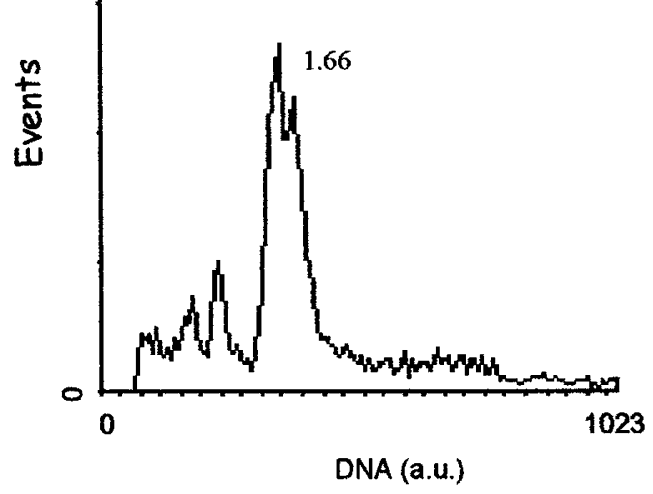

Figure 5.

Flow cytometric DNA histograms. A, Recurrent tumor showing an aneuploid peak with a DNA index of 0.64 , with respect to human female lymphocytes. B, Xenografted tumor developed from primary tumor, showing two aneuploid peaks. C, ch-2879 cells at passage 18, showing an unique aneuploid peak at DNA index of 1.38. D, Xenografted tumor developed after inoculation of ch-2879 cells in nude mice; an aneuploid peak with a DNA index of 1.29 was found. 


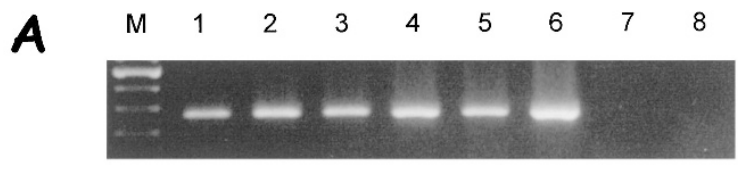

\section{$\begin{array}{lllllll}M & \text { PT } & X & \text { R } & \text { c.l. } & 5 & 6\end{array}$}

B

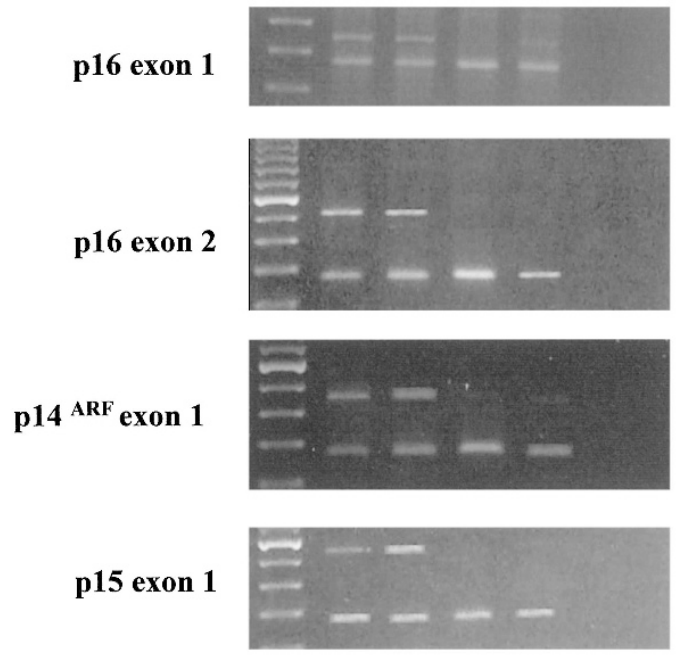

Figure 6.

A, RT-PCR showing collagen type $2 A$ transcripts. Lane $M$, molecular weight marker; lane 1, primary tumor; lane 2, xenograft from primary tumor; lane 3 , recurrence; lane 4, ch-2879 cell line; lane 5, ch-2879-A8 clone; lane 6, xenograft derived from cell line. B, Deletion of the $9 p 21$ genes was not found in the primary tumor $(P T)$, nor in the primary tumor xenografted $(X)$. Deletion was observed in the recurrence $(R)$ and in the cell line derived from the recurrence, ch-2879 (c.l.).

turally as conventional CS, although it was more dedifferentiated. The cells retained their proliferative activity. There were intratumoral blood vessels and some necrotic areas (Fig. 1D).

\section{Mycoplasma Detection}

ch-2879 cultured cells at passages 20 and 40 stained with Hoechst 33342 did not show mycoplasma contamination.

\section{Discussion}

CS represents the second most frequent primary malignancy of the skeleton. Grading of CS has proven prognostic value (Evans et al, 1977). The present case was a grade 3 , considering its high cellularity and the predominance of the myxoid matrix, with only sparse foci of chondroid appearance. The rapid local recurrence and distant metastases seem to be in accordance with those reported for high-grade tumors (Bjornsson et al, 1998; McAfee et al, 1985).

The biology of chondrogenic neoplasms is still, to a large extent, unstudied and unclear. Malignant transformation and progression of cartilage tumors seems to be associated with an increasing incidence of clonal chromosome aberrations, reflecting the multistep process of tumor development, involving activation of oncogenes, loss of tumor suppressor genes, and secondary or tertiary genetic alterations. In the present case, the cytogenetic studies showed that the primary tumor as well as the recurrence had a hyperhaploid karyotype with clonal numerical abnormalities and a sole structural anomaly. Only chromosomes 1q, 2, 5, $7,15,16,19,20,21$, and 22 were disomic. The rearrangement affected chromosomes 1 and 21, leading to the loss of the 1p segment. Most of chromosome 1 rearrangements observed in other tumor types such as in leiomyosarcomas, colorectal adenocarcinomas, and breast carcinomas, result in the loss of terminal $1 \mathrm{p}$ segments (Mitelman et al, 2002). Although abnormalities of chromosome 1 have been considered as a secondary cytogenetic event in CS (Gunawan et al, 2000), we must take into account that the rearranged chromosome observed in the present case also affects chromosome 21 in a similar manner to that previously reported in two mesenchymal CS (Naumann et al, 2002), in which a rearranged chromosome der(13;21) was common in both cases. In addition, seven cases have been reported in which the short arm of chromosome 21 was rearranged (Mitelman et al, 2002). It is not clear what kind of molecular impact this rearrangement, which affects the centromeric region of chromosome 21 , could imply. Furthermore, the primary tumor lost the entire chromosome 13. Loss of chromosome 13 has been associated with metastatic capacity in CS, probably as a result of genes associated with metastatic capacity located on chromosome 13 (Mandahl et al, 2002). It has also been suggested that loss of $13 q$ is a worse prognostic factor (Mandahl et al, 2002), which exerts an influence regardless of tumor size or histopathologic malignancy grade. This parameter could be important in identifying patients who require intensified treatment.

A continuous cell line was obtained from the recurrent tumor. This cell line showed a chromosome number of 64 at passages 18 and 25, indicating that the hypotriploid population was established in culture, originating from the hyperhaploid clone, through endomitosis or endoreduplication. As a consequence of this duplication, monosomic chromosomes in the hyperhaploid population would be underrepresented, and disomic chromosomes would be overrepresented, in relation to the triploid level. This fact suggests that polyploidization, common in CS, is an evolutionary pathway and has been associated with further progression toward high-grade CS (Bovee et al, 2000). In the present case, polyploidization, occurring in the first passage of the xenotransplanted tumor and early in the cell line, would represent, by the acquisition of two copies of the monosomic chromosomes, a selective advantage for those cells that have undergone extensive loss of heterozygosity. A comparison of cytogenetic and flow cytometry data showed a good correspondence between the two methods. Flow cytometric measurement of ploidy also shows the disappearance of the hyperhaploid population and the remnant of a unique hypotriploid population. 
Because suppression of one or more cell cycle control systems is a common finding in human malignancies, we studied p21, Rb, and p53 genes. Studies of the $\mathrm{p} 14^{\mathrm{ARF}}$ and $\mathrm{p} 16^{\mathrm{INK} 4 \mathrm{~A}}$ gene have been reported previously (Asp et al, 2000, 2001a, 2001b). Alterations in the $\mathrm{p} 16^{\mathrm{INK} 4 \mathrm{~A}}$ have been found in 6 of 22 human CS tissues, which were all grade 2 and 3 tumors; the majority of the alterations were increases in methylation rather than homozygous deletions of the gene. Alterations of $\mathrm{p} 14^{\mathrm{ARF}}$ have not previously been described in CS. It has been suggested that loss of $\mathrm{p} 16^{\mathrm{INK} 4 \mathrm{~A}}$ expression could be a key event in the malignant transformation of human CS cells (Asp et al, 2001b). Our results in the present study differ from this, because the deletion of the p16 gene did not occur in the initial process of malignant transformation (we did not detect the loss of p16 in the primary tumor) but in the tumoral progression. We suggest that inactivation of the 9p21 gene function could contribute to the high proliferative capacity shown not only by malignant cells in vivo but also in vitro by the cell line.

Type II collagen mRNA is expressed in the highgrade conventional CS (Aigner et al, 2002; Soderstrom et al, 2002) as an alternative splice variant of collagen type II, the collagen 2A characteristic of chondroprogenitor cells (Aigner, 2002; Oganesian et al, 1997). Generally, chondrocytes in culture do not maintain the synthesis of type II collagen (Elima and Vuorio, 1989), and few permanent cell lines of human CS expressing collagen type II have been reported (Chano et al, 1998; Chansky et al, 1998; Kunisada et al, 1998; Takigawa et al, 1989, 1991). We found that ch-2879 transcribes a cartilage-specific gene such as type $2 \mathrm{~A}$ collagen. In addition, these cells synthesize S-100 protein, which has been detected in chondrocytes (Weiss and Dorfman, 1986). Therefore, ch-2879 cells show a phenotype of well-differentiated hypertrophic chondrocytes.

In conclusion, the genetic instability of CS was demonstrated by the high percentage of monosomies and the variation of the ploidy status. In both cases polyploidization occurred early in the xenotransplants obtained from the primary tumor and the cell line established from the recurrence. Also, deletion of the $9 \mathrm{p} 21$ locus that occurs in the progression of the tumor in vivo, could be an important factor that contributes to therapy resistance and unfavorable outcome. Moreover, from these results it can be concluded that either a small fraction of tumor cells present at any single point in time could ultimately determine the clinical outcome or that malignancy is acquired as the tumor grows. Our results suggest that cell populations from cartilage neoplasms are unstable and that aggressive cells can rapidly emerge from populations that seem relatively indolent.

The newly established continuous cell line with its distinct growth characteristics and tumor phenotypes in vitro and in vivo could contribute to the knowledge of biology of CS. Because ch-2879 cells possess these characteristics, they could be useful not only in studies of the differentiated phenotypes of human chondrocytes but also in basic studies on the diagnosis, treatment, and etiology of human CSs.

\section{Materials and Methods}

\section{Case Report and Pathologic Diagnosis}

A 35-year-old woman was referred to our hospital in January 2000 for a protruding mass growing in the chest wall. Computerized axial tomography showed a $7.5 \times 6.2-\mathrm{cm}$ mass. There was no evidence of metastatic disease. Biopsy revealed a grade $3 \mathrm{CS}$. The tumor was resected. Serum electrolytes and complete blood count were normal. The tumor recurred at 7 months and was resected. Further chemotherapy and radiotherapy failed to prevent a second relapse and the tumor metastasized.

\section{Cell Culture and Establishment of Cell Line}

Tumor tissue samples from the primary and relapsed tumors were dissected under aseptic conditions and immediately immersed in sterile RPMI 1640 medium (Gibco BRL, Grand Island, New York) supplemented with $2 \%$ antibiotics and $0.05 \mathrm{mg} / \mathrm{ml}$ of gentamicin sulfate. Samples of the tumors were rinsed gently twice in PBS (Gibco BRL) with $2 \%$ antibiotics and minced; the fragments were disaggregated using $0.02 \%$ collagenase type II (Sigma, St. Louis, Missouri) in RPMI 1640 medium supplemented with $10 \%$ fetal bovine serum (Gibco BRL), 1\% L-glutamine, $200 \mathrm{~mm}$ (Gibco BRL), penicillin (50 U/ml), and streptomycin sulfate $(50 \mu \mathrm{g} / \mathrm{ml})$ (Gibco BRL) and incubated at $37^{\circ} \mathrm{C}$ for 20 minutes. The cells were seeded into $25-\mathrm{cm}^{2}$ tissue culture flasks (Nunc, Roskide, Denmark) containing $5 \mathrm{ml}$ of complete medium. The cultures were maintained in a humidified atmosphere at $5 \% \mathrm{CO}_{2}$ in air at $37^{\circ} \mathrm{C}$. The medium was replaced twice per week. A confluent cell layer was obtained at Day 21 of the primary culture of the original tumor and at Day 19 of the seeding of the recurrence. Subcultures were then made with $0.25 \%$ trypsin-1 mM EDTA (Gibco $B R L)$. Cells were stored under liquid $N_{2}$ in culture medium containing 5\% dimethylsulfoxide (Sigma).

\section{Growth Kinetics}

Normal growth kinetics were determined by trypsinizing the cultures in triplicate and resuspending the cells in medium. The viable cells were counted in a hemocytometer by dye exclusion with $0.1 \%$ trypan blue in PBS every 24 hours for 4 days. Doubling time of the cell population was estimated in a logarithmic growth phase.

\section{Cell Density and Plating Efficiency}

Using cells from 30 th passage, $10^{5}$ cells were seeded in a $25-\mathrm{cm}^{2}$ tissue culture flask. The formation of a confluent cell layer was confirmed as taking approximately 2 weeks. The cells were isolated by trypsinization, and the number of cells was counted, from which the cell density and saturation density were calcu- 
lated. Cells $\left(5 \times 10^{2}\right)$ were seeded in a $80-\mathrm{cm}^{2}$ culture flask and cultured for 15 days. The medium was aspirated and the cells were rinsed with PBS, fixed in 95\% ethanol, and stained with hematoxylin. The number of colonies in the culture flask was counted microscopically, and from this the plating efficiency was determined.

\section{Establishment of ch-2879 Clones}

A single-cell cloning by the limiting dilution method was performed using cells in the 18th passage as previously described (Gil-Benso et al, 2001). Briefly, cells were harvested from confluent monolayer cultures using trypsin-EDTA, resuspended in complete medium, and diluted to a density of 50 cells $/ \mathrm{ml}$. Twenty microliters of the cell suspension was plated separately in each well of 96-well plate polystyrene (Nunc). The formed colonies were subsequently trypsinized and seeded in 35-mm dishes (Nunc); the resulting clonal populations were expanded for morphologic and genetic studies. Three clones named A8, $\mathrm{B} 7$, and $\mathrm{C} 1$ were analyzed.

\section{Morphologic Studies}

The surgical samples were fixed in 10\% formaldehyde, paraffin embedded, and stained with hematoxylin and eosin (HE). The cultured cells were observed daily using a phase contrast microscope (Nikon Company, Tokyo, Japan); photographs were taken using a $\times 10$ and $\times 20$ objective on Kodak technical Pan film. For light microscopy observation, cells grown on Lab-Tek chamber slides (Miles Laboratories, Naperville, Illinois) were washed with PBS and fixed with cold acetone for 5 minutes.

\section{Immunohistochemical Characterization}

Immunohistochemistry by the indirect peroxidase method was performed on fresh-frozen tissue and paraffin sections from the original tumor, the relapsed tumor, and the xenografts. Antigen retrieval was performed with heat-induced epitope retrieval with autoclave at 1.5 atmospheres for 3 minutes in citrate buffer solution. Negative controls were applied by substitution of the primary antibody with PBS alone. The antibodies, their source of origin, and the dilutions used are shown in Table 1. ch-2879 cells were grown in chamber slides, growth medium was removed, and cells were rinsed with PBS, fixed in cold methanolacetone for 5 minutes, and air dried for 20 minutes. The cells reacted with each of the primary antibodies for 1 hour at room temperature. The attached antibodies were visualized by an avidin-biotin-peroxidase procedure (LSAB DAKO). The mAbs applied were, in addition to those included in Table 1, as follows: cell cycle proteins p14, dilution 1:100 (Neomarkers); p16, dilution 1:500 (Santa Cruz Biotechnology, Santa Cruz, California); p21, dilution 1:50 (Santa Cruz); p27, dilution 1:50 (Dako); Cyclin D1, dilution 1:20 (Novocastra); tumor suppressor Rb, dilution 1:200 (Neomarkers); c-erb-b2, dilution 1:50 (Novocastra); MDM2, dilution
1:50 (Novocastra); and the transcription regulator Fli-1, dilution 1:100 (Santa Cruz).

\section{Electron Microscopy}

Tissues for electron microscopy were fixed in glutaraldehyde for 2 hours, washed three times, and stored overnight in $0.1 \mathrm{M}$ cacodylate buffer $(\mathrm{pH} 7.4)$. Tissue was postfixed in $2 \%$ sodium-cacodylate buffered osmium tetroxide solution for 1.5 hours and embedded in Eponate 12 (Ted Pella, Redding, Louisiana). For ultrastructural studies, cultured cells from passage 18 were washed twice with PBS ( $\mathrm{pH} 7.4)$, fixed in situ with $3 \%$ glutaraldehyde in 0.1 cacodylate buffer $(\mathrm{pH} 7.4)$ for 60 minutes at room temperature, washed three times with cacodylate buffer, and stored overnight in the same buffer; cells were then scraped from the culture flasks. Cellular material was pelleted by centrifugation at $3000 \times g$ for 15 minutes and then postfixed with $2 \%$ osmium tetroxide for 2 hours in ice. After dehydration with increasing concentrations of ethanol, fixed tumoral tissues and fixed cells cultures were embedded in propylene oxide Eponate and then cutting into 1- $\mu \mathrm{m}$-thick sections. Sections were stained with toluidine blue to select, by light microscopy, representative fields of the tumor and cultures. Ultrathin sections were made with an ultramicrotome Reichert ultracut E (Leica, Inc., Deinfield, Illinois), stained with lead citrate and uranyl acetate, and observed under an electron microscope (JEOL JEM 1010, Tokyo).

\section{Cytogenetic Studies}

Cytogenetic analyses were made from a short-term culture of the primary tumor at 22 days of seeding, from the recurrent tumor at 19 days of seeding, and at passages 3, 18 and 25 of the cell line. Cells were prepared for karyotyping by incubating actively growing cultures with $0.02 \mu \mathrm{g} / \mathrm{ml}$ of Colcemid (Gibco BRL) for 75 minutes before harvest. Cells were disaggregated with trypsin-EDTA (Gibco BRL), exposed to a hypotonic treatment of $0.075 \mathrm{M} \mathrm{KCl}$ at $37^{\circ} \mathrm{C}$ for 20 minutes, and then fixed three times with 3:1 methanolglacial acetic acid. Air-dried chromosome spreads were banded by the Giemsa-trypsin method. C-banding stains were performed in recurrence metaphases. At least 25 metaphases were analyzed in each sample, and the karyotype was described according to guidelines of the ISCN (1995).

\section{Fluorescence In Situ Hybridization}

Slides for fluorescence in situ hybridization were prepared the day before the assay was performed. Whole chromosome painting probes were applied to the slides, using standard procedures, to confirm the origin of rearranged chromosomes. Counterstaining of metaphases was performed with 4',6-diamidine-2phenylindol-dihydrochloride. The probes used were WCP1 SpectrumGreen and WCP21 SpectrumOrange (Vysis, Downers Grove, Illinois). The fluorescent signal was detected using a Zeiss Axioplan 2 fluorescence 
microscope and an "in situ" imaging system "Isis" (Carl Zeiss Vision, Oberkochen, Germany).

\section{Heterologous Transplantation}

Two fragments of primary tumor, measuring 2- to 3-mm each, were inoculated into the back of 4- to 6-week-old male BALB/c nude mice, maintained in a specific pathogen-free room and observed for tumor development. When the transplanted tumor grew to 3 $\mathrm{mm}$ or more in maximal diameter, the mice were killed. Tumors were minced and transplanted again to other nude mice for serial heterotransplantation. Samples of the tumors were processed for histologic, immunohistochemical, electron microscopy, and genetic studies.

Tumorigenicity of the cell line was tested by heterotransplantation in 4- to 6-week-old nude mice. An inoculum of $2 \times 10^{6}$ cells suspended in PBS was subcutaneously injected into their right flank.

\section{Flow Cytometry}

Exponentially growing cells were harvested using trypsin and EDTA and resuspended in complete medium, washed twice in the same medium, twice in PBS, and filtered through a $30-\mu \mathrm{m}$ nylon mesh to remove clumped cells. Cells were fixed with cold $70 \%$ ethanol and stained with propidium iodide $(50 \mu \mathrm{g} / \mathrm{ml})$ containing RNase A (1 $\mu \mathrm{g} / \mathrm{ml})$ (Sigma). Human peripheral blood lymphocytes were used as control for diploid cells. Lymphocytes were isolated from whole blood using Lymphoprep separation medium (Nycomed Pharma AS, Oslo, Norway). Measurement of at least 10,000 nuclei was made using an Epics Elite cell sorter (Coulter Electronics Inc., Hialeah, Florida) with $15 \mathrm{~mW}$ of a 488-nm argon laser. Histogram data were analyzed with Mcycle software (Phoenix, Arizona). The ploidy level was expressed as the DNA index, which was 1.0 of the DNA index of diploid lymphocytes.

\section{Molecular Analyses}

Total RNA was extracted from frozen tissues and cultured cells using TRIzol reagent (Life Technologies, Rockville, Maryland) according to the manufacturer's instructions. One microgram was reverse transcribed with Maloney murine leukemia virus reverse transcriptase (Perkin Elmer, Madrid, Spain) using random primers in a final volume of $20 \mu \mathrm{l}$. The amplification step was performed in a Cetus Perkin Elmer 9600 thermal cycler using primers and cycling conditions previously described for the EWS-CHN, TAF2-CHN fusions (Okamoto et al, 2001) and type II collagen transcripts (Nakanishi et al, 2000; Sjogren et al, 1999). The integrity of the RNA for the RT-PCR was confirmed by amplification of the porphobilinogen deaminase (PBGD) and CDK4 transcripts using the following primer sequences: PBGD forward: 5'-TGTCTGGTAACGGCAATGCGGCTGCAAC-3'; PBGD reverse: 5'TCAATGTTGCCACCACACTGTCCGTCT-3'; CDK4 forward: 5'-ACAGGATCCCGGGCTGGCGTG-3'; and CDK4 reverse: 5'-AAGAATTCCCTCTCAGTGTCCAGAAG-3'. The PCR product was subjected to electro- phoresis through 2\% ultrapure agarose gel with ethidium bromide in tris-acetic acid-EDTA buffer.

DNA was isolated from frozen tissue samples and cultured cells. High molecular weight DNA was obtained by proteinase $\mathrm{K}$ (Life Technologies) digestion and purification using conventional phenol-chloroform protocol. Samples were analyzed for molecular alterations of the $\mathrm{G} 1$ to $\mathrm{S}$ phase cell cycle transition as previously described (López-Guerrero et al, 2001). dPCR was used to detect homozygous deletion of the 9p21 locus genes: the presence of homozygous deletion was confirmed by the loss of the PCR product corresponding to $\mathrm{p} 15^{\mathrm{INK} 4 \mathrm{~B}}, \mathrm{p} 16^{\mathrm{INK} 4 \mathrm{~A}}$, and $\mathrm{p} 14^{\mathrm{ARF}}$ genes with the presence of $\beta$-globin amplification. A water control with no DNA was included in each experiment. The methylation status of the $5^{\prime} \mathrm{CpG}$ island in the promoter region of the $\mathrm{p} 15^{\mathrm{INK} 4 \mathrm{~B}}$ and $\mathrm{p} 16^{\mathrm{INK} 4 \mathrm{~A}}$ genes was determined with the procedure described by Herman et al (1996) after chemical modification of the DNA and amplification with specific primers from the methylated and unmethylated DNA. Gene amplification of the MDM2, CDK4, and Cyclin D1 genes was determined by dPCR using two sets of primers, one corresponding to the target gene and the other to an internal control gene sequencethe dopamine receptor, the B-globin, and the INF $\gamma$ genes for MDM2, CDK4, and Cyclin D1 analysis, respectively. Identification of p53 mutations was performed by direct sequencing of exons 5 to 8 of the gene.

\section{Mycoplasma Detection}

To discard mycoplasma contamination, the ch-2879 cultured cells were stained with Hoechst 33342 (5 $\mu \mathrm{g} / \mathrm{ml}$ ) (Sigma) for 10 minutes at $37^{\circ} \mathrm{C}$ and examined with a fluorescence microscope at $\times 1000$ under oil immersion.

\section{Acknowledgements}

We thank Ms. Ana Clari and Ms. Estela Pons for their technical assistance.

\section{References}

Aigner T (2002). Towards a new understanding and classification of chondrogenic neoplasias of the skeleton: Biochemistry and cell biology of chondrosarcoma and its variants. Virchows Arch 441:219-230.

Aigner T, Muller S, Neureiter D, Illstrup DM, Kirchner T, and Bjornsson J (2002). Prognostic relevance of cell biologic and biochemical features in conventional chondrosarcomas. Cancer 94:2273-2281.

Asp J, Brantsing C, Benassi MS, Inerot S, Sangiorgi L, Picci $P$, and Lindahl A (2001a). Changes in p14(ARF) do not play a primary role in human chondrosarcoma tissues. Int $\mathrm{J}$ Cancer 93:703-705.

Asp J, Inerot S, Block JA, and Lindahl A (2001b). Alterations in the regulatory pathway involving $\mathrm{p} 16, \mathrm{pRb}$ and cdk4 in human chondrosarcoma. J Orthop Res 19:149-154. 
Asp J, Sangiorgi L, Inerot SE, Lindahl A, Molendini L, Benassi MS, and Picci P (2000). Changes of the p16 gene but not the p53 gene in human chondrosarcoma tissues. Int $\mathrm{J}$ Cancer 85:782-786.

Bjornsson J, McLeod RA, Unni KK, Ilstrup DM, and Pritchard DJ (1998). Primary chondrosarcoma of long bones and limb girdles. Cancer 83:2105-2119.

Bovee JV, Cleton-Jansen AM, Kuipers-Dijkshoorn NJ, van den Broek LJ, Taminiau AH, Cornelisse CJ, and Hogendoorn PC (1999). Loss of heterozygosity and DNA ploidy point to a diverging genetic mechanism in the origin of peripheral and central chondrosarcoma. Genes Chromosomes Cancer 26: 237-246.

Bovee JV, van Royen M, Bardoel AF, Rosenberg C, Cornelisse CJ, Cleton-Jansen AM, and Hogendoorn PC (2000). Near-haploidy and subsequent polyploidization characterize the progression of peripheral chondrosarcoma. Am J Pathol 157:1587-1595.

Bridge JA, Bhatia PS, Anderson JR, and Neff JR (1993). Biologic and clinical significance of cytogenetic and molecular cytogenetic abnormalities in benign and malignant cartilaginous lesions. Cancer Genet Cytogenet 69:79-90.

Chano T, Okabe H, Saeki Y, Ishizawa M, Matsumoto K, and Hukuda S (1998). Characterization of a newly established human chondrosarcoma cell line, CS-OKB. Virchows Arch 432:529-534.

Chansky H, Robbins JR, Cha S, Raskind WH, Conrad EU, and Sandell LJ (1998). Expression of cartilage extracellular matrix and potential regulatory genes in a new human chondrosarcoma cell line. J Orthop Res 16:521-530.

Dorfman HD and Czerniak B (1995). Bone cancers. Cancer 75:203-210.

Elima K and Vuorio E (1989). Expression of mRNAs for collagens and other matrix components in dedifferentiating and redifferentiating human chondrocytes in culture. FEBS Lett 4; 258:195-198.

Evans HL, Ayala AG, and Romsdahl MM (1977). Prognostic factors in chondrosarcoma of bone: A clinicopathologic analysis with emphasis on histologic grading. Cancer 40: 818-831.

Gil-Benso R, Martinez-Lorente A, Pellin-Perez A, NavarroFos S, Gregori-Romero MA, Carda C, Callaghan R, PeydroOlaya A, and Llombart-Bosch A (2001). Characterization of a new rat cell line established from 2 'AAF-induced combined hepatocellular cholangiocellular carcinoma. In Vitro Cell Dev Biol Anim 37:17-25.

Gunawan B, Weber M, Bergmann F, Wildberger J, Niethard FU, and Fuzesi L (2000). Clonal chromosome abnormalities in enchondromas and chondrosarcomas. Cancer Genet Cytogenet 120:127-130.

Herman JG, Graff JR, Myohanen S, Nelkin BD, and Baylin SB (1996). Methylation-specific PCR: A novel PCR assay for methylation status of $\mathrm{CpG}$ islands. Proc Natl Acad Sci USA 93:9821-9826.

Hirabayashi Y, Ishida T, Yoshida MA, Kojima T, Ebihara Y, Machinami R, and Ikeuchi T (1995). Translocation (9;22)(q22; q12): A recurrent chromosome abnormality in extraskeletal myxoid chondrosarcoma. Cancer Genet Cytogenet 81:3337.

ISCN (1995). An International System for Human Cytogenetic Nomenclature. Basel, Switzerland: Karger.
Johnson S, Tetu B, Ayala AG, and Chawla SP (1986). Chondrosarcoma with additional mesenchymal component (dedifferentiated chondrosarcoma). I. A clinicopathologic study of 26 cases. Cancer 58:278-286.

Kunisada T, Miyazaki M, Mihara K, Gao C, Kawai A, Inoue H, and Namba M (1998). A new human chondrosarcoma cell line (OUMS-27) that maintains chondrocytic differentiation. Int $J$ Cancer 77:854-859.

Labelle Y, Zucman J, Stenman G, Kindblom LG, Knight J, Turc-Carel C, Dockhorn-Dworniczak B, Mandahl N, Desmaze C, Peter M, et al (1995). Oncogenic conversion of a novel orphan nuclear receptor by chromosome translocation. Hum Mol Genet 4:2219-2226.

Lee FY, Mankin HJ, Fondren G, Gebhardt MC, Springfield DS, Rosenberg AE, and Jennings LC (1999). Chondrosarcoma of bone: An assessment of outcome. J Bone Joint Surg Am 81:326-338.

López-Guerrero JA, Pellin A, Noguera R, Carda C, and Llombart-Bosch A (2001). Molecular analysis of the 9p21 locus and p53 genes in Ewing family tumors. Lab Invest 81:803-814.

Lundberg AS and Weinberg RA (1999). Control of the cell cycle and apoptosis. Eur J Cancer 35:1886-1894.

Mandahl N, Gustafson P, Mertens F, Akerman M, Baldetorp B, Gisselsson D, Knuutila S, Bauer HC, and Larsson O (2002). Cytogenetic aberrations and their prognostic impact in chondrosarcoma. Genes Chromosomes Cancer 33:188-200.

Martin JA, Forest E, Block JA, Klingelhutz AJ, Whited B, Gitelis S, Wilkey A, and Buckwalter JA (2002). Malignant transformation in human chondrosarcoma cells supported by telomerase activation and tumor suppressor inactivation. Cell Growth Differ 13:397-407.

McAfee MK, Pairolero PC, Bergstralh EJ, Piehler JM, Unni KK, McLeod RA, Bernatz PE, and Payne WS (1985). Chondrosarcoma of the chest wall: Factors affecting survival. Ann Thorac Surg 40:535-541.

Mitelman F, Johansson B, and Mertens F, editors (2002). Mitelman database of chromosome aberration in cancer. http://cgap.nci.nih.gov/chromosomes/Mitelman.

Nakanishi T, Nishida T, Shimo T, Kobayashi K, Kubo T, Tamatani T, Tezuka K, and Takigawa M (2000). Effects of CTGF/Hcs24, a product of a hypertrophic chondrocytespecific gene, on the proliferation and differentiation of chondrocytes in culture. Endocrinology 141:264-273.

Naumann S, Krallman PA, Unni KK, Fidler ME, Neff JR, and Bridge JA (2002). Translocation der(13;21)(q10;q10) in skeletal and extraskeletal mesenchymal chondrosarcoma. Mod Pathol 15:572-576.

Okamoto S, Hisaoka M, Ishida T, Imamura T, Kanda $H$, Shimajiri S, and Hashimoto H (2001). Extraskeletal myxoid chondrosarcoma: A clinicopathologic, immunohistochemical, and molecular analysis of 18 cases. Hum Pathol 32: 1116-1124.

Oganesian A, Zhu Y, and Sandell LJ (1997). Type IIA procollagen amino propeptide is localized in human embryonic tissues. J Histochem Cytochem 45:1469-1480.

Sharpless NE and DePinho RA (1999). The INK4A/ARF locus and its two gene products. Curr Opin Genet Dev 9:22-30.

Sjogren H, Meis-Kindblom J, Kindblom LG, Aman P, and Stenman $G$ (1999). Fusion of the EWS-related gene TAF2N to 
TEC in extraskeletal myxoid chondrosarcoma. Cancer Res 59:5064-5067.

Soderstrom M, Bohling T, Ekfors T, Nelimarkka L, Aro HT, and Vuorio E (2002). Molecular profiling of human chondrosarcomas for matrix production and cancer markers. Int $\mathrm{J}$ Cancer 100:144-151.

Stenman G, Andersson H, Mandahl N, Meis-Kindblom JM, and Kindblom LG (1995). Translocation t(9;22)(q22;q12) is a primary cytogenetic abnormality in extraskeletal myxoid chondrosarcoma. Int J Cancer 62:398-402.

Takigawa M, Pan HO, Kinoshita A, Tajima K, and Takano Y (1991). Establishment from a human chondrosarcoma of a new immortal cell line with high tumorigenicity in vivo, which is able to form proteoglycan-rich cartilage-like nodules and to respond to insulin in vitro. Int $\mathrm{J}$ Cancer 48:717-725.
Takigawa M, Tajima K, Pan HO, Enomoto M, Kinoshita A, Suzuki F, Takano Y, and Mori Y (1989). Establishment of a clonal human chondrosarcoma cell line with cartilage phenotypes. Cancer Res 49:3996-4002.

Turc-Carel C, Dal Cin P, Rao U, Karakousis C, and Sandberg AA (1988). Recurrent breakpoints at $9 q 31$ and $22 q 12.2$ in extraskeletal myxoid chondrosarcoma. Cancer Genet Cytogenet 30:145-150.

Weiss AP and Dorfman HD (1986). S-100 protein in human cartilage lesions. J Bone Joint Surg Am 68:521-526. 